\title{
Differential Anti-Inflammatory Effects of Three Purified Omega Unsaturated Fatty Acids on Collagen-Induced Arthritis in Mouse
}

\author{
Pamela Izaret Pérez-Martínezיㅜ, Víctor Gabriel Hernández², Oscar Rodríguez-Espinosa1, \\ Patricia Arce-Paredes' ${ }^{1}$ Oscar Rojas-Espinosa ${ }^{1}$ \\ ${ }^{1}$ Departamentos de Inmunología, Escuela Nacional de Ciencias Biológicas, Instituto Politécnico Nacional, \\ Ciudad de México, México \\ ${ }^{2}$ Departamentos de Morfología, Escuela Nacional de Ciencias Biológicas, Instituto Politécnico Nacional, \\ Ciudad de México, México \\ Email: rojas_espinosa@hotmail.com
}

Received 16 June 2016; accepted 30 July 2016; published 2 August 2016

Copyright (C) 2016 by authors and Scientific Research Publishing Inc.

This work is licensed under the Creative Commons Attribution International License (CC BY). http://creativecommons.org/licenses/by/4.0/

(c) (i) Open Access

\section{Abstract}

Background: The Mediterranean Diet (MD) has been linked to a reduced risk of developing degenerative diseases, including atherosclerosis, heart stroke, diabetes, arthritis and cancer. However, only a few scientific investigations have attempted to validate this impression. The ingredients of the MD include significant amounts of omega $(\omega 3, \omega 6$, and $\omega 9)$ unsaturated fatty acids (UFAs). A few studies of these UFAs in the prevention or treatment of arthritis have yielded controversial results, but a general belief regarding their beneficial effects has prevailed. Objective: To investigate the effects of three relevant UFAs, namely Docosahexaenoic Acid (DHA), Arachidonic Acid (AA), and Oleic Acid (OA) ( $\omega 3, \omega 6$, and $\omega 9$, respectively), in the development of arthritis using a murine model of Collagen-Induced Arthritis (CIA). Methods: DBA-1 mice were immunized with chicken collagen type II (CII) and were subsequently treated with $\omega$-UFAs for 53 days. Dexamethasone (DEXA) was used as a positive anti-inflammatory agent. The effect of the treatments was evaluated through several parameters: inflammation indices, antibody levels, cell proliferation, and histopathological findings. Results and Conclusion: The anti-inflammatory effect of the tested substances was inversely correlated with the histopathological findings: a greater antiinflammatory effect was associated with less articular damage. Oleic acid $(\omega 9)$ was the most efficient anti-inflammatory UFA, followed by DHA and then AA. DEXA completely inhibited the development of arthritis, whereas the untreated CII-immunized mice developed the most severe articular damage. DBA-1 mice with CII-induced arthritis constitute an adequate model for the study of arthritis and its treatment. 
Keywords

Collagen, CIA, DBA-1 Mice, Omega-UFAs, Dexamethasone, Anti-Inflammatory

\section{Introduction}

Rheumatoid Arthritis (RA) is an autoimmune, inflammatory chronic disease that primarily affects the diartroidal articulations, damaging both cartilage and bone. The disease evolves gradually, initiating with articular pain and inflammation of hands; then feet are also affected. At the long run RA produces systemic manifestations such as myalgia, tiredness, weight loss, depression, fever and anorexia. At this stage the mortality rate is high resulting from cardiovascular, infectious, hematologic, gastrointestinal, and lung complications.

The disease has an overall prevalence of $0.5 \%$ to $1.0 \%$ and a variable annual incidence of 12 to 1200 per 100,000 inhabitants, depending on factors such as ethnicity, sex, age, and life style. RA is three times more frequent in women than in men, and hormonal changes are blamed for that.

The origin of RA is multifactorial and immunologic, genetic, dietetic, and environmental factors are recognized as key participants. All elements of the immune response are implicated in the pathology of the disease but CD4+T cells Th1 and Th17 are the orchestrating populations. T cells drive B cells to produce antibodies to collagen, proteoglycans, matrix proteins, IgG, and citrullinated peptides; $\mathrm{T}$ cells stimulate $\mathrm{T}$ cells, macrophages, fibroblasts, and endothelial cells to release a wide range of cytokines (IFN $\gamma$, TNF, IL-1, IL-6, IL-17, etc.) which participate in the recruiting and activation of additional inflammatory cells, including new T cells, B cells, mast cells, and neutrophils. All of these cells and cytokines participate in the articular and systemic damage of arthritis.

Rheumatoid Arthritis (RA) is a disease for which a definitive cure has not been found. This lack of a cure has motivated the development of several animal models to not only better understand the immunopathology of the disease but also test new anti-inflammatory drugs that may arrest progression of the disease.

Among the several models developed, DBA-1 (H-2q) mice with Collagen-Induced Arthritis (CIA) represent the model that most resembles the human pathology and in which most new treatments have been investigated [1]-[3]. Inflammation of the front and rear paws, including edema and erythema, appears within one month following immunization with type II collagen and then progresses to marked synovitis, which ultimately leads to articular ankylosis. Pannus infiltration of the synovia with erosion of the cartilage and subchondral bone constitutes characteristic features of the disease, and T- and B-lymphocytes, macrophages, neutrophils, and fibroblasts are the predominant cellular components of the pannus and the cells responsible for the observed articular damage [2] [3].

The treatment of arthritis is routinely performed with conventional Disease-Modifying Anti-Rheumatic Drugs (cDMARDs), including methotrexate, sulfasalazine, leflunomide and chloroquine [4]-[6]; most of these agents, however, have different long-term side effects. In addition, blockers of kinases in proinflammatory signalling cascades have recently been developed and successfully tested in RA trials, but their routine use has not yet been approved by the FDA [7].

An alternative treatment for arthritis involves the use of nutriments enriched in Unsaturated Fatty Acids (UFAs), namely omega $3(\omega 3)$ and $\omega 9$. It has been noted that eating a diet rich in fish, olive oil (and other oils), and vegetal fibre (the so-called Mediterranean diet) considerably reduces the risk of developing a series of chronic degenerative illnesses, such as atherosclerosis [8], coronary disease [9], RA [10], psoriasis [11], diabetes mellitus [12] and even cancer [13] [14]. Most of these beneficial effects have been attributed to fish oil, a rich source of $\omega 3$ fatty acids, and olive oil, a rich source of $\omega 9$ fatty acids. In RA, for instance, a great deal of information regarding the beneficial effects of foods and supplements enriched in omega fatty acids (mainly $\omega 3$ UFAs) has been reported. In most of these studies, supplements were administered in addition to conventional therapy [10] [15], but few studies have been conducted with isolated fatty acids [16] [17]. The present study simultaneously analysed the effects of three purified UFAs, namely docosahexaenoic $(\omega 3)$, arachidonic $(\omega 6)$ and oleic $(\omega 9)$ fatty acids, in the prevention of collagen-induced arthritis in mouse in the absence of any other treatment and evaluated the inflammatory changes. 


\section{Materials and Methods}

\subsection{Reagents}

Unless otherwise indicated, the reagents, including omega fatty acids, were purchased from Sigma Chemical Co. (St Louis, MO, USA).

\subsection{Mice}

Six-week-old female DBA-1 mice were purchased from Harlan (Indianapolis, IN, USA). Upon arrival, the mice were handled according to the Official Mexican Norm for the Correct Use of Small Experimental Animals (NOM-062-ZOO-1999), and the project was sanctioned by the Institutional Ethical Research Committee (Approval document: CEI-ENCB 16/01/2014).

\subsection{Collagen Type II (CII)}

Collagen was isolated from chicken sterna following the procedure and indications described by Inglis et al. (2008) [18]. The purity of CII was assessed by polyacrylamide gel electrophoresis (PAGE) under reducing conditions.

\subsection{Freund Adjuvant}

Incomplete and complete (4 mg/ml Mycobacterium tuberculosis) Freund adjuvants were purchased from MD Bioproducts (St. Paul, MN, USA).

\subsection{Collagen Type II (CII) Inoculum}

An emulsion of CII-CFA was prepared following the recommendations provided by Bevaart et al. [19] and Rosloniec et al. [3].

\subsection{Immunization}

Arthritis was induced by subcutaneously injecting $50 \mu \mathrm{l}$ of CII in complete Freund's adjuvant (CFA) into each side of the tail base (for a total of $300 \mu \mathrm{g} /$ mouse). The inoculum was prepared by admixing $6 \mathrm{mg}$ of collagen dissolved in $1.0 \mathrm{ml}$ of $0.1 \mathrm{M}$ acetic acid with an equal volume of CFA (4 mg of killed M. tuberculosis/ml). A booster consisting of the same amount of collagen in incomplete Freund's adjuvant was administered 15 days later. Non-inoculated DBA-1 mice were also included in the study as a control.

\subsection{Treatment}

Six groups of 5 mice each were distributed and treated as indicated in Table 1. The dosages of omega-UFAs and dexamethasone were calculated from the dosages administered to humans suffering from a great variety of

Table 1. DBA-1 mice distribution, immunization, and treatment.

\begin{tabular}{cccc}
\hline Group & CII-immunization (and boost) & Daily treatment & Starting treatment \\
\hline 1 & None & None & None \\
2 & Day 0 (day 14) & None & None \\
3 & Day 0 (day 14) & DEXA $(1.0 \mathrm{mg} / \mathrm{kg})$ & Day 0 \\
4 & Day 0 (day 14) & DHA $(\omega 3)(1.0 \mathrm{mg})^{*}$ & Day 0 \\
5 & Day 0 (day 14) & AA $(\omega 6)(1.0 \mathrm{mg})^{*}$ & Day 0 \\
6 & Day 0 (day 14) & OA $(\omega 9)(1.0 \mathrm{mg})^{*}$ & Day 0 \\
\hline
\end{tabular}

DEXA, dexamethasone; DHA, docosahexaneoic acid; AA, arachidonic acid; OA, oleic acid. *All omega UFAs were administered dissolved in light mineral oil (Sigma-Aldrich, St. Louis MO, USA. 
disorders, particularly arthritis (36 - $54 \mathrm{mg} / \mathrm{kg}$ of body weight). For a mouse weighing $20-25 \mathrm{~g}$, this dosage ranged from 1.0 to $1.1 \mathrm{mg}$ of the UFAs, which is a dose similar to that successfully used in a study with only DHA [17]. For treatment, UFAs were dissolved in light mineral oil to a concentration of $10 \mathrm{mg} / \mathrm{ml}$, and $0.1 \mathrm{ml}$ of the solution was administered daily via the gastric route through a ball-ended metal cannula. The control mice received plain mineral oil.

\subsection{Arthritis Assessment}

Arthritis development was assessed a) through daily measurement of the paws' thickness using a clock-type calliper (Mitutoyo 7301, Tokyo, Japan) and b) through the daily recording of the inflammatory changes (edema, erythema, swelling) in each paw according to the following scale: fingers/toes (1 point each), wrists/ankles (5 points each), and acute pain ( 1 point per limb), resulting in a total of 11 points per paw (44 points per mouse). The presence of pain was deduced if the mouse exhibited an uncomfortable reaction during measurement of the pad thickness. The inflammatory changes were monitored for 53 days. The measurements and evaluation of inflammation were performed by a single trained person, who was not informed of the administered treatment, and the experimental groups were labelled with a numerical code (from 01 to 06 ).

\subsection{Lymphoproliferation}

At the end of the study, suspensions of splenocytes from each mouse were prepared in Dulbecco's Modified Eagle's Medium (DMEM-FCS), plated in quadruplicate into 96-well plates at a density of $5 \times 10^{5}$ cells per well, and stimulated with a) DMEM-FCS or b) C-II (4.0 $\mathrm{\mu g} /$ well). The functionality of the assay was established in cell cultures stimulated with concanavalin-A ( $0.5 \mu \mathrm{g} /$ well). Stimulated and non-stimulated spleen cells were incubated for $72 \mathrm{~h}$ at $37^{\circ} \mathrm{C}$ with $4 \% \mathrm{CO}_{2}$. At the end of the incubation time, $20 \mu \mathrm{l}$ of MTT (7.5 mg/ml in PBS) was added to each well, and the plates were returned to the incubator for an additional 6 hours. The plates were then centrifuged (700× $\mathrm{g} / 7 \mathrm{~min})$, and the sediment (blue formazan) was dissolved overnight with $200 \mu \mathrm{l}$ of $10 \%$ SDS in $0.1 \mathrm{~N} \mathrm{NaOH}$. The colored solution was analysed using an ELISA reader (Multiskan Plus, Labsystems, Finland) at $540 \mathrm{~nm}$.

\subsection{Antibody Measurement}

Anti-collagen antibodies in the sera of all of the experimental animals were measured using an enzyme-linked immunosorbent assay (ELISA). The assay was a standard protocol and consisted of a) overnight coating of the ELISA wells with $5.0 \mu \mathrm{g}$ of $\mathrm{CII}$ in $0.1 \mathrm{ml}$ of $0.05 \mathrm{M}$ Tris- $0.2 \mathrm{M} \mathrm{NaCl}$ at $\mathrm{pH} 7.5$; b) blocking of the wells with $0.2 \mathrm{ml}$ of $3 \%$ skim milk in $0.15 \mathrm{M}$ PBS for $30 \mathrm{~min}$; c) incubation for $2 \mathrm{~h}$ with $0.1 \mathrm{ml}$ of the sera diluted 1:100, 1:500 and 1:1000 in PBS; d) incubation for $1 \mathrm{~h}$ with $0.1 \mathrm{ml}$ of HRP-goat anti mouse immunoglobulin antibody diluted 1:000 in PBS; and e) detection of the antigen-antibody complexes with $0.1 \mathrm{ml}$ of a chromogenic mixture (3 mg of orthophenylene diamine and $10 \mu \mathrm{l}$ of 30\% hydrogen peroxide in $10 \mathrm{ml}$ of $0.01 \mathrm{M}$ acetate buffer, $\mathrm{pH}$ 6.0). Between these steps, the wells were washed 3 times for 5 min each with PBS. After the addition of $20 \mu \mathrm{l}$ of $8 \mathrm{~N}_{2} \mathrm{SO}_{4}$ to terminate the reaction, the absorbance of the colored product was determined using a Multiskan Plus ELISA reader (Finland) at $492 \mathrm{~nm}$.

\subsection{Histopathological Analysis}

The mice were sacrificed by $\mathrm{CO}_{2}$ inhalation and were bled by heart puncture. Their rear and front pads were then amputated, maintained in 10\% buffered formalin for 3 days, decalcified in EDTA-PBS for 3 - 4 weeks and processed for paraffin inclusion and sectioning according to a standard procedure. The sections were stained with haematoxylin-eosin for general histopathology.

\subsection{Statistical Analysis}

The pad thickness and inflammation indexes were analysed by Student's $t$ test for 2 independent means (one-tailed hypothesis) at a significance level of 0.05 . The lymphoproliferation results and the antibody levels were analysed by the Mann-Whitney U test using a one-tailed hypothesis and z-ratio at a significance level of 0.05 . 


\section{Results}

\subsection{Collagen-Induced Arthritis in the Mouse}

More than $80 \%$ of the mice immunized with type II collagen developed a marked inflammatory reaction reminiscent of arthritis in humans. Inflammatory changes appeared by day 11, but the arthritis became overt by day 21 in the mice that received a booster on day 14. Representative images of the rear pads of a healthy mouse and a CII-immunized mouse are shown in Figure 1. Mice receiving diverse treatments showed inflammatory responses that ranged between these two extremes.

\subsection{Mice Immunized with CII Developed Progressive Paw Swelling}

The inflammatory changes (measured with inflammation indices) that occurred in the mice immunized with CII are illustrated in Figure 2. The results showed that the untreated mice developed an inflammatory response that progressed until the end of the 53-day study period. In contrast, dexamethasone controlled the inflammatory reaction from the beginning of the treatment, and the omega fatty acids showed intermediate effects between these two extreme results. The analysis of the effects observed at the end of the study showed that the least effective UFA was arachidonic $(\omega 6)$ acid and that the most effective was oleic $(\omega 9)$ acid, closely followed by DHA $(\omega 3)$ acid.

\subsection{Inflammation in the Front Pads of DBA-1 Mice Was More Frequent and More Serious than Inflammation in the Rear Pads}

Figure 3 shows the kinetics of the thickening in the front paws of DBA-1 mice subjected to the different treatments, and the kinetics of the stiffening in the rear paws are shown in Figure 4. Dexamethasone inhibited the development of CIA from the beginning of the treatment. Arachidonic $(\omega 6)$ acid had an inhibitory effect during most of the study but then lost its inhibitory effects, and the inflammatory activity of CII in this group increased to the level observed in the untreated CIA mice. Omega 9 and $\omega 3$ fatty acids behaved in a comparable manner: treatment of the CIA-mice with $\omega 9$ and $\omega 3$ UFAs reduced the inflammatory reaction by more than $50 \%$ and by close to $30 \%$, respectively. Thus, although both the rear and front paws became inflamed, the inflammatory reaction was more frequent and more serious in the front paws. The comparison of the pad thicknesses and inflammation indices yielded basically the same results.


Figure 1. Thickness of the rear paws of healthy (upper panel) and CIA (lower panel) DBA-1 mice measured 53 days after CII immunization. CIA mice subjected to treatment with dexamethasone presented pads similar to healthy pads, but the mice treated with $\omega 3$, $\omega 6$ and $\omega 9$ UFAs showed variable degrees of inflammation (see text). 


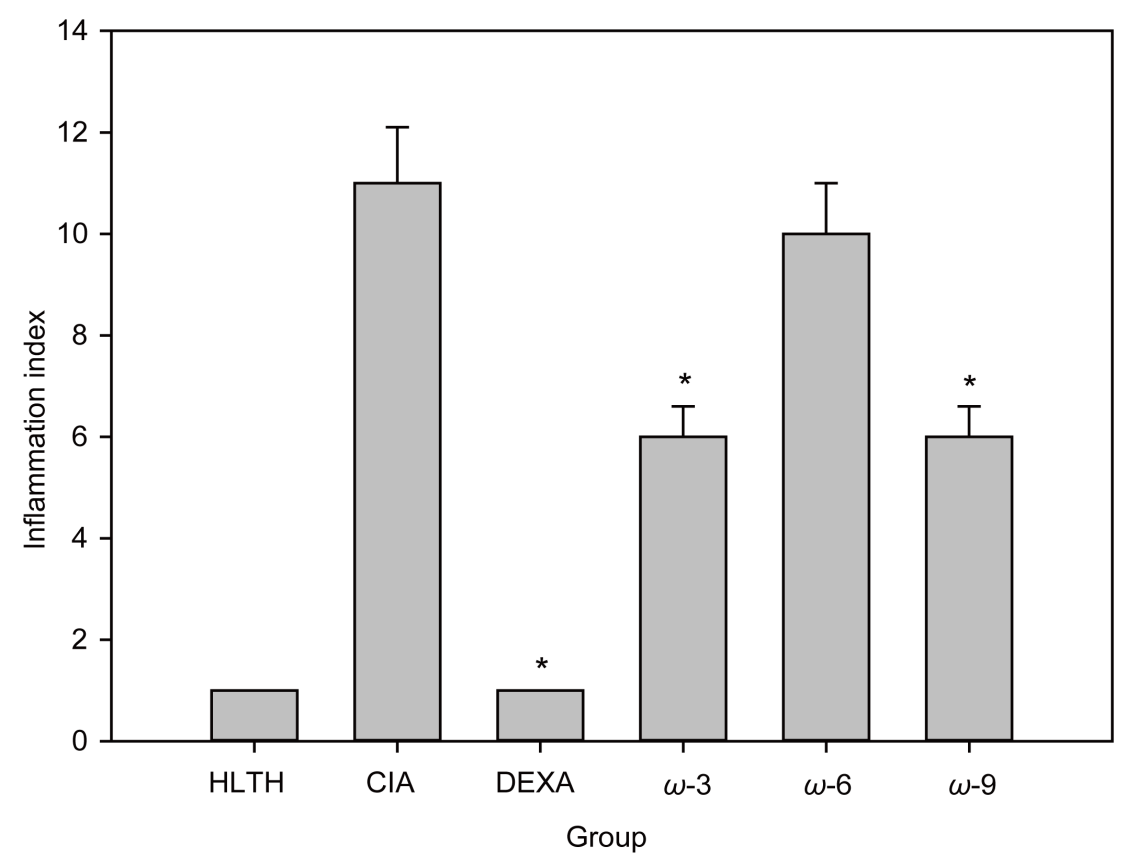

Figure 2. Inflammation indices of the paws of DBA-1 mice immunized with CII subjected to different treatments over 53 days. HLTH, healthy mice; CIA, untreated CIA mice; DEXA, CIA mice treated with dexamethasone; $\omega 3$, CIA mice treated with docosahexaenoic acid; $\omega 6$, CIA mice treated with arachidonic acid; $\omega 9$, CIA mice treated with oleic acid. Asterisks indicate those values that were significantly different $(<0.05)$ from the value obtained in CIA mice (one-tailed Student's $t$ test for 2 independent means).

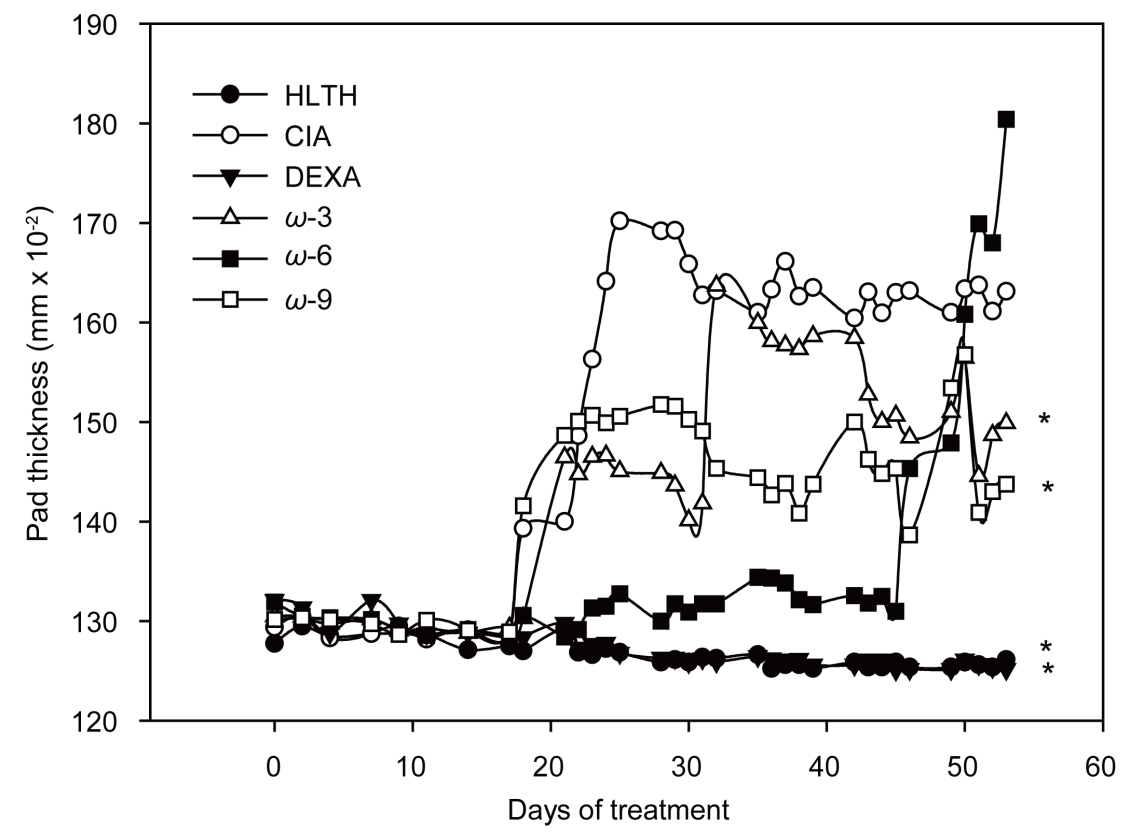

Figure 3. Thicknesses of the front paws of DBA-1 mice immunized with C-II subjected to different treatments for 53 days. HLTH, healthy mice; CIA, mice with collagen-induced arthritis; DEXA, CIA mice treated with dexamethasone; $\omega 3$, CIA mice treated with docosahexaenoic acid; $\omega 6$, CIA mice treated with arachidonic acid; $\omega 9$, CIA mice treated with oleic acid. Asterisks indicate those values that were significantly decreased in relation to those found in the untreated CIA group (one-tailed Student's $t$ test for 2 independent means, $\mathrm{p}<$ $0.05)$. 


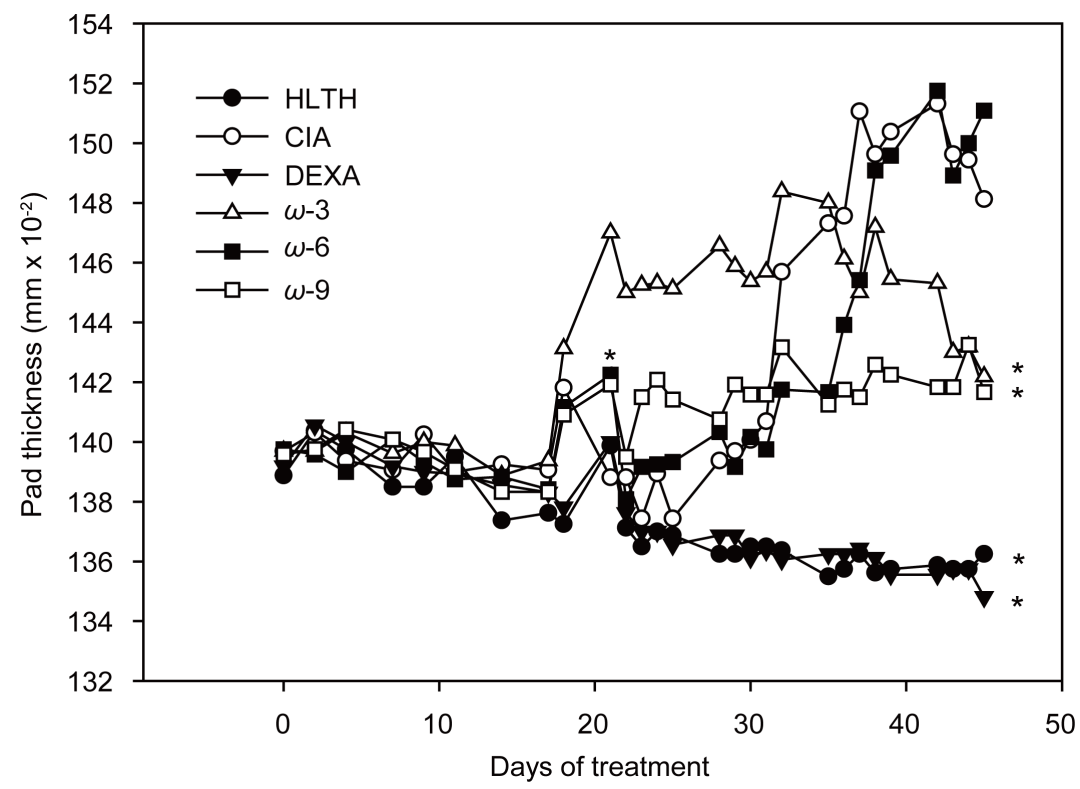

Figure 4. Thickness of the rear paws of DBA-1 mice immunized with C-II, subjected to different treatments for 53 days. HLTH, healthy mice; CIA, mice with collagen-induced arthritis; DEXA, CIA-mice treated with dexamethasone; $\omega 3$, CIA-mice treated with docosahexaenoic acid; $\omega 6$, CIA-mice treated with arachidonic acid; $\omega 9$, CIA-mice treated with oleic acid. Asterisks point at those values that resulted statistically diminished in relation to the CIA untreated group (one-tailed Student $t$ test for 2 independent means, $\mathrm{p}<0.05$ ).

\subsection{Histological Changes}

The footpads of healthy and CIA mice subjected to the diverse treatments showed variable degrees of articular involvement; a brief description of the most conspicuous alterations, which includes a composite description of the changes observed within each group, is provided below. The articular damage degree (DD) was rated from none (0) to maximal (4+) according to the histopathologist's expertise and description. Images representative of the several observed changes are shown in Figure 5.

\subsubsection{Carpus Joints}

The carpus joints of healthy (HLTH) mice showed a normal histology: a straight synovial space and capsule, neat bone surfaces, and integrity of the cartilage and bone with normal numbers and morphologies of chondrocytes and osteocytes. The CIA mice presented extensive tissue infiltration consisting of macrophages, lymphocytes, fibroblasts, and some PMN cells, obliterating the synovial space and eroding the bone, which are changes indicative of an active ongoing inflammatory process (DD 4+). The dexamethasone (DEXA)-treated CIA mice presented an essentially normal bone architecture with some pannus $(\mathrm{P})$ on the bone surface and some bone erosion (BE) (DD 0-1+). The docosahexaenoic acid ( $\omega 3$ )-treated CIA mice showed remnants of tissue infiltration (IT) and emerging tissue regeneration (RT) (DD 1-2+). The arachidonic acid ( $\omega 6$ )-treated CIA mice showed extensive tissue infiltration with extreme bone destruction and complete loss of the articular architecture (DD 4+). The oleic acid $(\omega 9)$-treated CIA mice showed a restored architecture, with cleared synovial spaces and a predominance of young chondrocytes and osteoclasts in the regenerating bones (DD 0-1+).

\subsubsection{Metatarsal-Phalangeal Joints}

The metatarsal-phalangeal articulations of healthy (HLTH) mice showed intact bones and synovial spaces as well as normal cellularity of the bone and cartilage (DD 0). The articular bones of a CIA mouse showed extensive inflammatory tissue (IT), bone destruction (BE), and obliterated synovial space (DD 4+). The DEXAtreated CIA mice showed a normal structure of the articular bones and synovial space (DD 0). The $\omega 3-$ and $\omega 9$ treated CIA mice showed a predominant repairing reaction, with regenerating tissue (RT) consisting of young chondrocytes and osteoclasts, and synovial spaces with a relatively neat appearance (DD 1-2+). The $\omega 6$-treated 

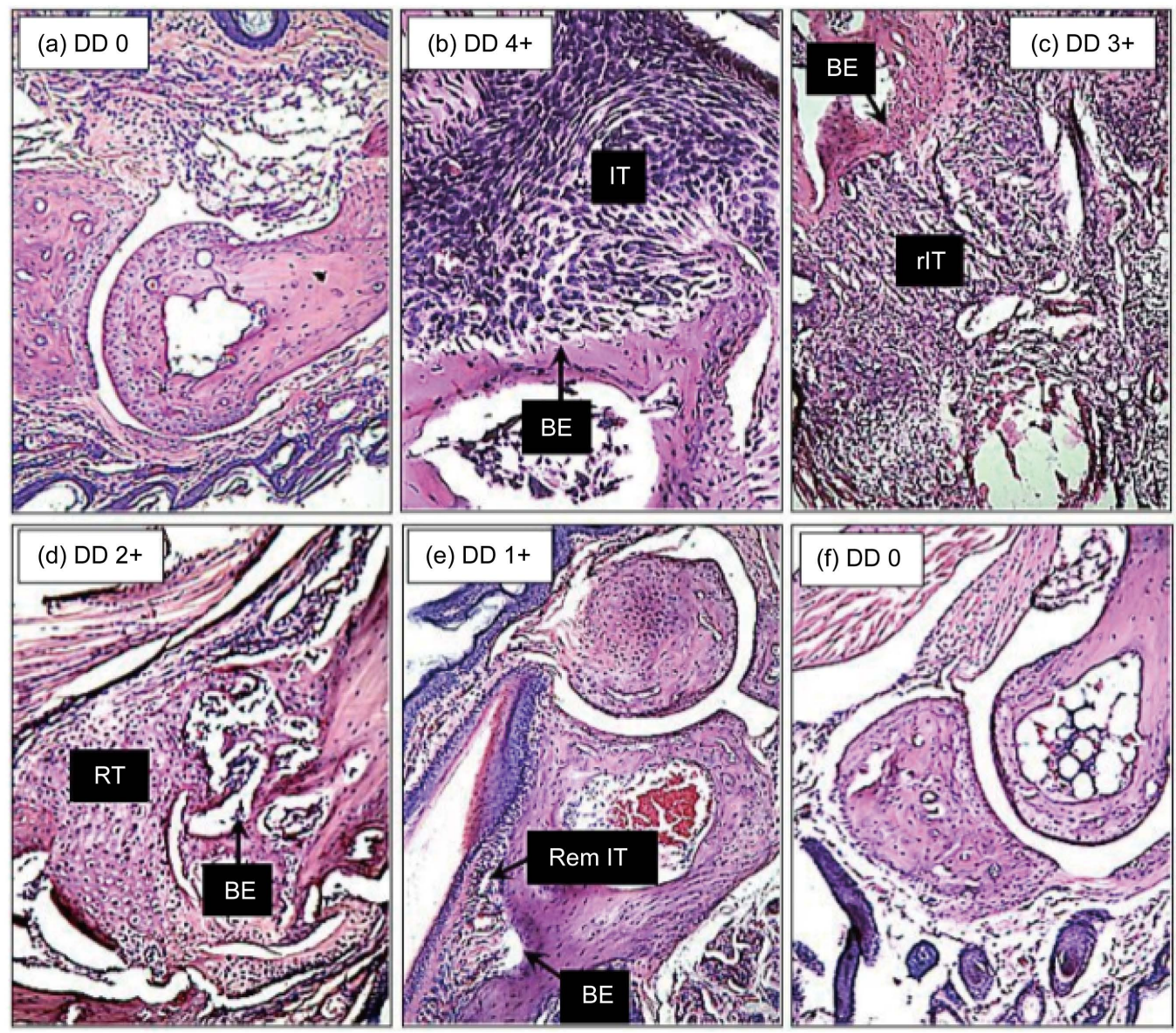

Figure 5. Composite image of the tarsal articular bones of (a) healthy DBA-1 mice, (b) CIA mice, and CIA mice treated with (c) arachidonic acid, (d) DHA, (e) oleic acid, or (f) dexamethasone for 53 days. BE refers to bone erosion/destruction, rIT refers to recovering inflammatory tissue, RT refers regenerating tissue, and RemIT refers to remnant inflammatory tissue. The degree of damage (DD) is indicated on each image. A detailed description of the observed changes in each set of articulations is presented in the Results Section (Histological changes) of the manuscript (hematoxylin-eosin, 10×).

CIA mice showed articular bones that were extensively damaged by inflammatory tissue rich in blood vessels, mononuclear cells and PMN cells (DD 4+).

\subsubsection{Tarsus Joints}

The tarsal articulations of the normal mice (HLTH) showed intact cartilage and bone tissue, smooth articular surfaces, clean synovial spaces and normal chondrocyte and osteoclast cellularity (DD 0). The CIA mice showed tarsal articulations with evident inflammatory tissue obliterating the synovial space and marked bone destruction (DD 4+). The DEXA-treated CIA mice showed a normal bone articular architecture (DD 0). The $\omega 3$ - and $\omega 6$-treated CIA mice presented articulations showing the sequel of bone erosion (BE) and an ongoing development of tissue regeneration (RT) (DD 2+). The $\omega 9$-treated CIA mice showed a completely normal articular architecture (DD 0).

\subsubsection{Tibia-Calcaneus-Tarsus Joints}

These bones in a healthy (HLTH) articulation showed a normal histology with intact bone surfaces, clean synovial spaces, and normal cellularity of osteoclasts and chondrocytes (DD 0). In CIA mice, these articulations showed a significant amount of inflammatory tissue (IT) consisting of macrophages, lymphocytes and a variable number of PMN cells with evident erosion of the bones and obliterated synovial spaces (DD 4+). The dexamethasone (DEXA)-treated CIA mice showed an articular structure similar to that of HLTH mice (DD 0). The $\omega 3$ - and $\omega 6$-treated CIA mice showed articular bones with only remnants of tissue inflammation and regenera- 
tion (RT) of the articular cartilage (DD 1+). The $\omega 9$-treated CIA mice showed articular structures with no obvious signs of inflammation but with proliferating regeneration tissue (RT) consisting of young chondrocytes (DD $0)$.

The above-described alterations were semi-quantified using an arbitrary damage degree (DD) scale (Table 2), and the numeric values are graphically illustrated in Figure 6.

As observed, although with some inconsistences, the worst inflammatory damage occurred in the limbs of the untreated CIA mice (DD 4+), followed by the CIA mice treated with arachidonic ( $\omega 6)$ acid (DD 3.18+), then the CIA mice treated with docosahexaenoic ( $\omega 3$ ) acid (DD 1.75+), and finally the CIA mice treated with oleic $(\omega 9)$ acid (DD 0.5+). The limbs of the CIA mice treated with dexamethasone (DEXA) appeared as healthy as the limbs of normal mice (DD $0.25+$ ).

Table 2. Effect of dexamethasone, $\omega 3, \omega 6$ and $\omega 9$-UFAs on the development of collagen-induced arthritis in DBA-1 mice.

\begin{tabular}{|c|c|c|c|c|c|c|}
\hline \multicolumn{7}{|c|}{ Mice group } \\
\hline & HLTH & CIA & CIA-DEXA & CIA-W3 & CIA-W6 & CIA-W9 \\
\hline \multicolumn{7}{|c|}{ Damage degree (DD) } \\
\hline Carpus joints ${ }^{*}$ & 0 & $4+$ & $0-1+$ & $1-2+$ & $4+$ & $0-1+$ \\
\hline Metatarsal falangeal joints ${ }^{*}$ & 0 & $4+$ & 0 & $1-2+$ & $4+$ & $1+$ \\
\hline Tarsus joints ${ }^{*}$ & 0 & $4+$ & 0 & $2+$ & $2+$ & 0 \\
\hline Tibia-calcaneous joints $^{* *}$ & 0 & $4+$ & $0+$ & $1+$ & $1+$ & 0 \\
\hline
\end{tabular}

${ }^{*}$ Hand joints, ${ }^{* *}$ Foot joints, ${ }^{* * *} \mathrm{DD}$ in the mouse of each group that showed the most severe alterations.

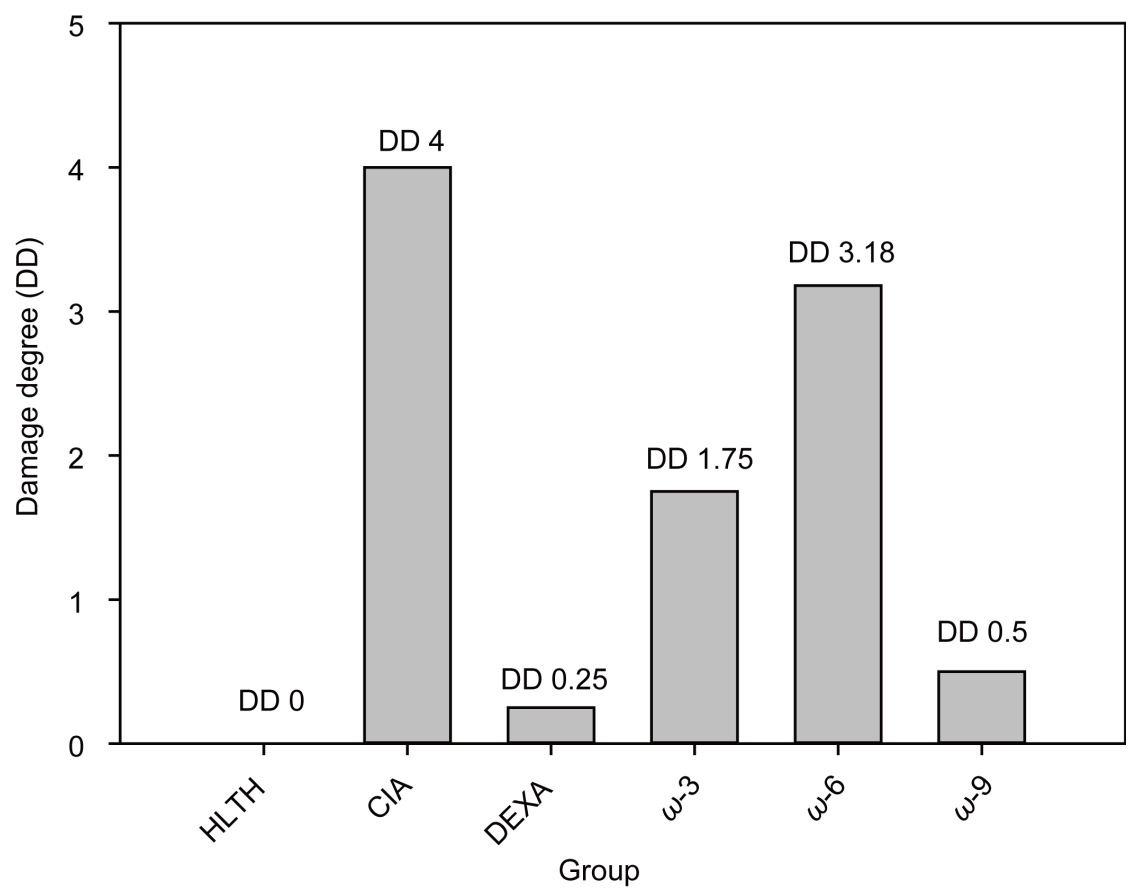

Figure 6. Average damage degree (DD) in the articulation tissues of DBA-1 mice immunized with CII and treated with diverse substances for 53 days. HLTH, healthy mice; CIA, mice with collageninduced arthritis; DEXA, mice treated with dexamethasone; $\omega 3$, mice treated with docosahexaenoic acid; $\omega 6$, mice treated with arachidonic acid; $\omega 9$, mice treated with oleic acid. The data were obtained by taking into account all of the animals in each group that showed the maximal histological alterations. 


\subsection{The Splenocytes of CIA-Mice Treated with the Omega UFAs Showed a Depressed Proliferative Response to CII}

Figure 7 illustrates the lymphoproliferative response of spleen cells taken from healthy (HLTH) mice and from CIA mice treated with mineral oil, dexamethasone (DEXA), DHA, AA, or OA. The 3 omega UFAs tested depressed the lymphoproliferative response to CII to levels comparable to those observed in the healthy group. Dexamethasone also had a significant inhibitory effect, but this effect was less marked than that observed with any of the UFAs tested. In all cases, compared with the CIA group, the inhibitory effects observed were highly significant $(\mathrm{P}<0.05)$.

\subsection{Treatment of CIA Mice with Omega UFAs Did Not Significantly Affect Their Humoral Response to CII}

Even though the Mann-Whitney test suggested a significant difference between the group of mice treated with OA $(\omega 3)$ and the untreated CIA group, this difference was not clearly reflected in the graphical illustration of the results. Dexamethasone did not significantly affect the anti-CII antibody levels (Figure 8).

\section{Discussion}

A series of reports have linked the Mediterranean diet with a low risk of chronic inflammatory degenerative diseases, and some of these have reported curative effects. The beneficial effects observed have been attributed to the polyphenols and monounsaturated fatty acids (UFA) contained in the Mediterranean diet's nourishments (MDNs) (fish, olive oil, fresh vegetables and fruits, almonds, nuts, etc.). The anti-inflammatory effects of the MDNs have been experimentally studied with oils and derivatives, and the results have shown that polyphenols and oleuropein aglycones extracted from extra-virgin olive oil have a marked anti-inflammatory effect in a murine model of collagen-induced arthritis. These two types of compounds decreased joint edema, pannus accumulation,

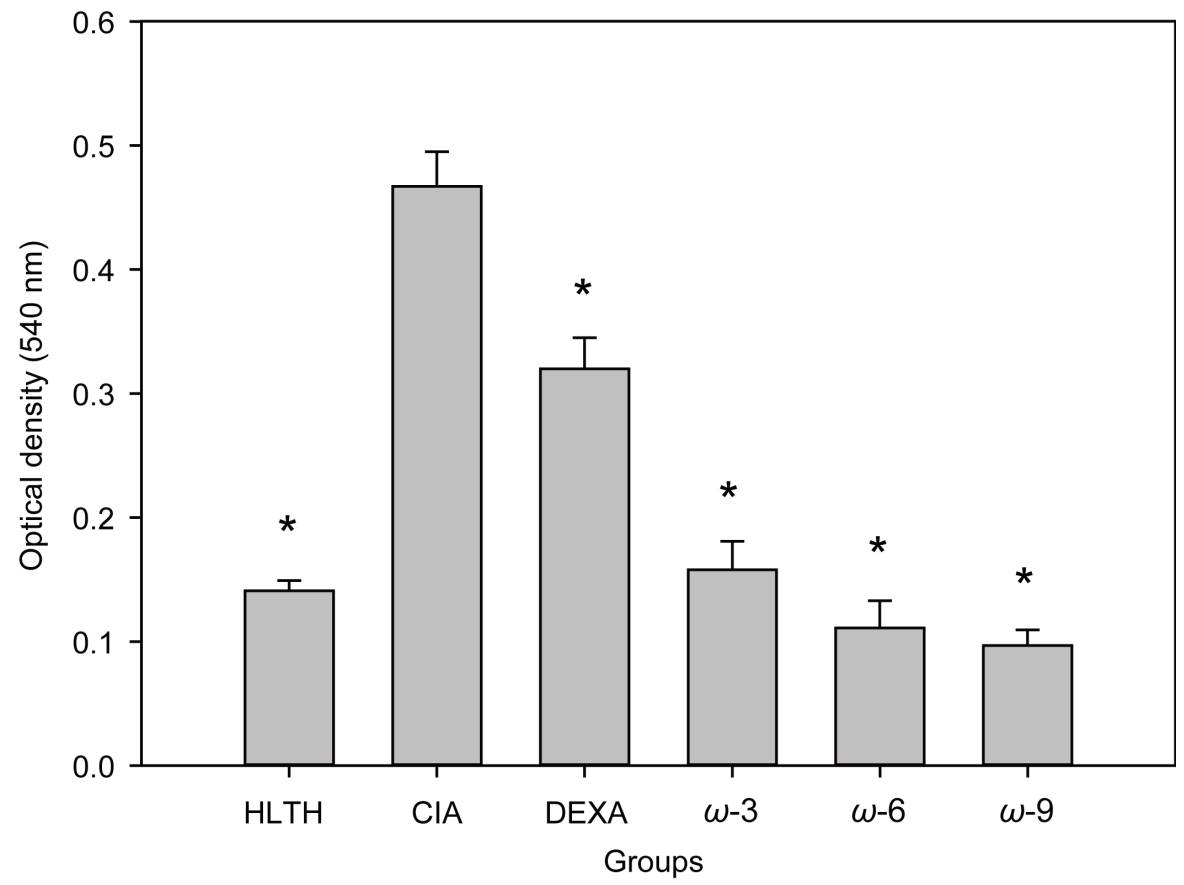

Figure 7. Lymphoproliferative response to CII of CIA mice subjected to different treatments for 53 days. HLTH, healthy mice; CIA, mice with CIA; DEXA, CIA mice treated with dexamethasone; $\omega 3$, CIA mice treated with DHA; $\omega 6$, CIA mice treated with arachidonic acid; $\omega 6$, CIA mice treated with oleic acid. The data are the average values \pm 1 SD of the 5 animals in each group. Asterisks ( $\left(^{*}\right)$ indicate the values that were significantly different from those obtained in the untreated CIA group ( $\mathrm{p}<0.05)$. MTT reduction test. 




Figure 8. Anti-CII antibody levels in the sera of healthy and CIA-DBA-1 mice subjected to different treatments for 53 days. HLTH, healthy mice; CIA, mice with CIA; DEXA, CIA mice treated with dexamethasone; $\omega 3$, CIA mice treated with DHA; $\omega 6$, CIA mice treated with arachidonic acid; $\omega 9$, CIA mice treated with oleic acid. Data are the average values \pm 1 SD of the 5 animals in each group. Asterisks $\left(^{*}\right)$ indicate those values that were significantly different from those obtained in the untreated CIA group ( $\mathrm{p}<0.05$ ); according to the Mann-Whitney U test with a one-tailed hypothesis and z-ratio, only oleic acid showed a significant inhibitory effect (ELISA).

cartilage degradation and bone erosion by reducing the levels of pro-inflammatory cytokines and prostaglandin E2, the expression of cyclooxygenase 2, and the level of microsomal prostaglandin E synthase-1 [20] [21]. In addition, the Greenland-Eskimo diet, in which the basic nourishment consists of seal, whale and fish meat, all of which are rich in $\omega 3$ UFAs, has also been recognized to exert beneficial effects. In the present study, we comparatively tested the prophylactic effects of the purified UFAs docosahexaenoic acid (DHA, $\omega 3$ ), arachidonic acid (AA, $\omega 6)$ and oleic acid (OA, $\omega 9$ ) in a murine model of collagen-induced arthritis (CIA). Female DBA-1 mice were immunized with chicken collagen type II, and treatment with light mineral oil (the UFA vehicle), dexamethasone, DHA, AA, or OA was started the following day and continued for 53 days. The effects of the treatments were monitored over a period of 53 days on the basis of two parameters: thickness of the paws and inflammation indices. The final effects on day 53 were analysed through a histopathological examination of the pads. The lymphoproliferative response (cell-mediated immunity) and the level of antibodies (humoral immunity) to CII were also evaluated in the present study.

There were clear correlations between the paw thickness and the inflammation indices tested, with the front paws showing the highest degree of inflammation. OA $(\omega 9)$ and DHA $(\omega 3)$ showed the greatest anti-inflammatory effects, whereas AA $(\omega 6)$ exerted the least effects. Additionally, there was a direct correlation between the inflammatory and histopathological changes. At the end of the study, i.e., on day 53, prominent inflammatory infiltration with overt articulation damage was observed in the untreated CIA mice, and only slightly less inflammation was observed in the animals treated with arachidonic $(\omega 6)$ acid. In contrast, some islets of inflammatory tissue continued to be observed in the CIA mice treated with oleic acid $(\omega 9)$ and, to a lesser extent, in those treated with docosahexaenoic $(\omega 3)$ acid, but the presence of regenerative tissue with obvious signs of cartilage and bone repair (abundance of young chondrocytes and osteoclasts, respectively) was the predominant feature. The lower anti-inflammatory activity of arachidonic acid was comprehensible because this acid, when metabolized through the inducible cyclooxygenase pathway, produces eicosanoids (prostaglandins, thromboxanes and leukotrienes), which are metabolites with strong pro-inflammatory activity. In contrast, the beneficial effects of oleic and docosahexaenoic acids appear to be related to their ability to give rise to resolvins and protectins, which decrease inflammatory infiltration by interfering with signalling pathways related to the activation 
of $\mathrm{NF} \kappa \mathrm{B}$, a transcription factor necessary for the synthesis of pro-inflammatory cytokines, including cellrecruiting chemokines [22]. Oleic acid (OA) has many documented effects on the immune system that could explain its anti-inflammatory activity observed in the present study. Although several cells appear to be affected by oleic acid in different manners, inhibition of the lymphoproliferative response of $\mathrm{T}$ cells has been one of the most consistent findings [23], a finding that was corroborated in the present study. A similar effect has been described for oily fish rich in $\omega 3$ DHA [24].

Several in vitro studies have shown that $\omega 3$ UFAs interact and amalgamate with the membrane lipids of lymphocytes, thereby affecting their function, including cell migration, adhesion, diapedesis, and cell proliferation [25]. DHA and OA block the synthesis of IL-2 by interfering with the activity of MAPK, STAT5a/b, AKT, and ERK1/2, arresting the transition from G0 to G1 [25] [26]. In addition, the metabolism of oleic and linoleic acids leads to the synthesis and accumulation of triglycerides and ceramides, which have been proven to be toxic to and apoptogenic in lymphocytes [27] [28]. All of these data support the beneficial effects of oleic acid and DHA in arresting the development of CIA in mouse. These results increase the opportunity for the molecular study of omega UFAs as anti-inflammatory agents in arthritis and other inflammatory diseases.

The finding that most of the tested UFAs and dexamethasone had a minor effect on the production of antiC-II antibodies indicates that humoral immunity to CII has a small participation in this murine model of collagen-induced arthritis. Oleic acid, however, had a moderate down-regulating effect on the antibody response to C-II (Mann-Whitney test), perhaps by affecting the helping activity of Th cells on B cells.

In summary, the results show that oleic acid $(\omega 9)$ was the more efficient anti-inflammatory UFA for the CIA murine model, and this finding has to be taken into account when designing alternative treatments for arthritis in humans.

\section{Conclusion}

This paper, the first where three purified omega unsaturated fatty acids are comparatively studied, corroborates previous findings on the anti-inflammatory effect of $\omega-3$ DHA and unveils a better effect of $\omega-9$ OA. A diet rich in these $\omega$-UFAs may improve the anti-inflammatory effect of the conventional disease modifying anti-rheumatic drugs currently used in the treatment of arthritis.

\section{Acknowledgements}

O.R-E designed and directed the investigation; PIP-M performed the experiments; OR provided technical assistance; VGH provided the histopathological descriptions of the tissue sections; PA-P contributed to the graphics and statistical treatment of the data used in the article. Financial support came from the Secretaría de Investigación y Posgrado (SIP) of the Instituto Politécnico Nacional, Mexico (Projects: 20140667/20150600). O.R-E is a fellow holder of grants from COFAA (IPN), EDI (IPN), and SNI (México).

\section{Conflict of Interest}

None.

\section{References}

[1] Asquith, D.L., Miller, A.M., McInnes, I.B. and Liew, F.Y. (2009) Animal Models of Rheumatoid Arthritis. European Journal of Immunology, 39, 2040-2044. http://dx.doi.org/10.1002/eji.200939578

[2] Brand, D.D., Kang, A.H. and Rosloniec, E.F. (2003) Immunopathogenesis of Collagen Arthritis. Seminars in Immunopathology, 25, 3-18. http://dx.doi.org/10.1007/s00281-003-0127-1

[3] Rosloniec, E.F., Cremer, M., Kang, A.H., Myers, L.K. and Brand, D.D. (2010) Collagen-Induced Arthritis. Current Protocols in Immunology, 15, 1-25. http://dx.doi.org/10.1002/0471142735.im1505s89

[4] Meier, F.M.P., Frerix, M., Hermann, W. and Müller-Ladner, U. (2013) Current Immunotherapy in Rheumatoid Arthritis. Immunotherapy, 5, 955-974. http://dx.doi.org/10.2217/imt.13.94

[5] Lopez, M.A., Siddhanamatha, H.R., Shea, B., Tugwell, P., Wells, G.A. and Suarez, M.E. (2014) Methotrexate for Treating Rheumatoid Arthritis. Cochrane Database of Systematic Reviews, 10, 6.

[6] Visser, K. and van der Heijde, D. (2009) Optimal Dosage and Route of Administration of Methotrexate in Rheumatoid Arthritis: A Systematic Review of the Literature. Annals of the Rheumatic Diseases, 68, 1094-1099. 
http://dx.doi.org/10.1136/ard.2008.092668

[7] Bonilla-Hernán, M.G., Miranda-Carús, M.E. and Martin-Mola, E. (2011) New Drugs beyond Biologics in Rheumatoid Arthritis: The Kinase Inhibitors. Rheumatology, 50, 1542-1550. http://dx.doi.org/10.1093/rheumatology/ker192

[8] Gardener, H., Wright, C.B., Cabral, D., Scarmeas, N., Gu, Y., Cheung, K., Elkind, M.S., Sacco, R.L. and Rundek, T. (2014) Mediterranean Diet and Carotid Atherosclerosis in the Northern Manhattan Study. Atherosclerosis, 2, 303-310. http://dx.doi.org/10.1016/j.atherosclerosis.2014.03.011

[9] Estruch, R., Ros, E., Salas-Salvadó, J., Covas, M.I., Corella, D., Arós, F., Gómez-Gracia, E., Ruiz-Gutiérrez, V., Fiol, M., Lapetra, J., Lamuela-Raventos, R.M., Serra-Majem, L., Pintó, X., Basora, J., Muñoz, M.A., Sorlí, J.V., Martínez, J.A. and Martínez-González, M.A. (2013) Primary Prevention of Cardiovascular Disease with a Mediterranean Diet. New England Journal of Medicine, 368, 1279-1290. http://dx.doi.org/10.1056/NEJMoa1200303

[10] Lee, Y.H., Bae, S.C. and Song, G.G. (2012) Omega-3 Polyunsaturated Fatty Acids and the Treatment of Rheumatoid Arthritis: A Meta-Analysis. Archives of Medical Research, 43, 356-362.

http://dx.doi.org/10.1016/j.arcmed.2012.06.011

[11] Barrea, L., Balato, N., DiSomma, C., Macchia, P.E., Napolitano, M., Savanelli, M.C., Esposito, K., Colao, A. and Savastano, S. (2015) Nutrition and Psoriasis: Is There Any Association between the Severity of the Disease and Adherence to the Mediterranean Diet? Journal of Translational Medicine, 13, 18. http://dx.doi.org/10.1186/s12967-014-0372-1

[12] Salas-Salvadó, J., Bulló, M., Babio, N., Martínez-González, M.Á., Ibarrola-Jurado, N., Basora, J., Estruch, R., Covas, M.I., Corella, D., Arós, F., Ruiz-Gutiérrez, V. and Ros, E. (2011) Reduction in the Incidence of Type Diabetes with the Mediterranean Diet. Diabetes Care, 34, 14-19. http://dx.doi.org/10.2337/dc10-1288

[13] Fiala, M. (2015) Curcumin and Omega-3 Fatty Acids Enhance NK Cell-Induced Apoptosis of Pancreatic Cancer Cells but Curcumin Inhibits Interferon- $\gamma$ Production: Benefits of Omega-3 with Curcumin against Cancer. Molecules, 20, 3020-3026. http://dx.doi.org/10.3390/molecules20023020

[14] Castelló, A., Pollán, M., Buijsse, A., Ruiz, A., Casas, A., Baena-Cañada, J.E., Lope, V., Antolín, S., Ramos, M., Muñoz, M., Lluch, A., de Juan-Ferré, A., Jara, C., Jimeno, M.A., Rosado, P., Díaz, E., Guillem, V., Carrasco, E., Pérez-Gómez, B., Vioque, J., Boeing, H. and Martín, M. (2014) Spanish Mediterranean Diet and Other Dietary Patterns and Breast Cancer Risk: Case-Control EpiGEICAM Study. British Journal of Cancer, 111, 1454-1462. http://dx.doi.org/10.1038/bjc.2014.434

[15] Gheita, T., Kamel, S., Helmy, N., El-Laithy, N. and Monir, A. (2012) Omega-3 Fatty Acids in Juvenile Idiopathic Arthritis: Effect on Cytokines (IL-1 and TNF- $\alpha$ ), Disease Activity and Response Criteria. Clinical Rheumatology, 31, 363-366. http://dx.doi.org/10.1007/s10067-011-1848-5

[16] Olson, M.V., Liu, Y.C., Dangi, B., Paul Zimmer, J., Salem Jr., N. and Nauroth, J.M. (2013) Docosahexaenoic Acid Reduces Inflammation and Joint Destruction in Mice with Collagen-Induced Arthritis. Inflammation Research, 62, 1003-1013. http://dx.doi.org/10.1007/s00011-013-0658-4

[17] Torres-Guzman, A.M., Morado-Urbina, C.E., Alvarado-Vazquez, P.A., Acosta-Gonzalez, R.I., Chávez-Piña, A.E., Montiel-Ruiz, R.M. and Jimenez-Andrade, J.M. (2014) Chronic Oral or Intra-Articular Administration of Docosahexaenoic Acid Reduces Nociception and Knee Edema and Improves Functional Outcomes in a Mouse Model of Complete Freund's Adjuvant-Induced Knee Arthritis. Arthritis Research \& Therapy, 10, R64.

[18] Inglis, J., Simelyte, E., McCann, F., Criado, G. and Williams, R. (2008) Protocol for the Induction of Arthritis in C57BL/6 Mice. Nature Protocols, 4, 612-618. http://dx.doi.org/10.1038/nprot.2008.19

[19] Bevaart, L., Vervoordeldonk, M.J. and Tak, P.P. (2010) Collagen Induced Arthritis in Mice. In: Proetzel, G. and Wiles, M.V., Eds., Mouse Models for Drug Discovery, Methods in Molecular Biology, Humana Press, New York City, 181192. http://dx.doi.org/10.1007/978-1-60761-058-8_11

[20] Rosillo, M.A., Alcaraz, M.J., Sánchez-Hidalgo, M., Fernández-Bolaños, J.G., Alarcón-de-la-Lastra, C. and Ferrándiz, M.L. (2014) Anti-Inflammatory and Joint Protective Effects of Extra-Virgin Olive-Oil Polyphenol Extract in Experimental Arthritis. The Journal of Nutritional Biochemistry, 12, 1275-1281. http://dx.doi.org/10.1016/j.jnutbio.2014.07.006

[21] Impellizzeri, D., Esposito, E., Mazzon, E., Paterniti, I., DiPaola, R., Morittu, V.M., Procopio, A., Britti, D. and Cuzzocrea, S. (2011) Oleuropein Aglycone, an Olive Oil Compound, Ameliorates Development of Arthritis Caused by Injection of Collagen Type II in Mice. Journal of Pharmacology and Experimental Therapeutics, 339, 859-869. http://dx.doi.org/10.1124/jpet.111.182808

[22] Singer, P., Shapiro, H., Theilla, T., Anbar, R., Singer, J. and Cohen, J. (2008) Anti-Inflammatory Properties of Omega3 Fatty Acids in Critical Illness: Novel Mechanisms and an Integrative Perspective. Intensive Care Medicine, 34, 15801592. http://dx.doi.org/10.1007/s00134-008-1142-4

[23] Yaqoob, P., Newsholme, E.A. and Calder, P.C. (1994) The Effect of Dietary Lipid Manipulation on Rat Lymphocyte 
Subsets and Proliferation. Immunology, 82, 603-6010.

[24] Calder, P.C. (2010) Omega-3 Fatty Acids and Inflammatory Processes. Nutrients, 2, 355-374. http://dx.doi.org/10.3390/nu2030355

[25] Gorjao, R., Cury-Boaventura, M.A., Martins, T. and Curi, R. (2007) Regulation of Human Lymphocyte Proliferation by Fatty Acids. Cell Biochemistry and Function, 25, 305-315. http://dx.doi.org/10.1002/cbf.1388

[26] Kim, H.J., Vosseler, C.A., Weber, P.C. and Erl, W. (2005) Docosahexaenoic Acid Induces Apoptosis in Proliferating Human Endothelial Cells. Journal of Cellular Physiology, 204, 881-888. http://dx.doi.org/10.1002/jcp.20351

[27] Gorjao, R., Cury-Boaventura, M.A., Kanunfre, C.C., Martins, T. and Curi, R. (2006) Mechanisms Involved in Jurkat Cell Death Induced by Oleic and Linoleic Acids. Clinical Nutrition, 25, 1004-1014. http://dx.doi.org/10.1016/j.clnu.2006.05.008

[28] Hofmanová, J., Vaculová, A., Lojek, A. and Kozubík, A. (2005) Interaction of Polyunsaturated Fatty Acids and Sodium Butyrate during Apoptosis in HT-29 Human Colon Adenocarcinoma Cells. European Journal of Nutrition, 44, 40-51. http://dx.doi.org/10.1007/s00394-004-0490-2

\section{Submit or recommend next manuscript to SCIRP and we will provide best service for you:}

Accepting pre-submission inquiries through Email, Facebook, LinkedIn, Twitter, etc.

A wide selection of journals (inclusive of 9 subjects, more than 200 journals)

Providing 24-hour high-quality service

User-friendly online submission system

Fair and swift peer-review system

Efficient typesetting and proofreading procedure

Display of the result of downloads and visits, as well as the number of cited articles

Maximum dissemination of your research work

Submit your manuscript at: http://papersubmission.scirp.org/ 